\title{
Presentación
}

\section{Educación media superior en Iberoamérica: aportaciones a las prácticas y políticas educativas de la región}

\section{Marta Cristina Azaola*}

La educación media superior (EMS), también conocida como bachillerato o secundaria alta, no tiene carácter obligatorio en la mayoría de los países de la región iberoamericana. En las últimas décadas, organismos internacionales de carácter neoliberal han tenido una gran influencia a nivel global respecto a asentar los objetivos para la población en edad de acceder y concluir la EMS; por ejemplo, de acuerdo con la Organización para la Cooperación y el Desarrollo Económicos (OCDE), el objetivo de la EMS es preparar a los estudiantes para continuar su formación superior o ingresar a mercados laborales competitivos. La OCDE señala que en este nivel se consolidan las competencias y los conocimientos básicos de los estudiantes. En la mayoría de los países miembros, la EMS es el nivel de educación más comúnmente alcanzado, lo cual permite mayor empleabilidad y mejor remuneración económica (OCDE, 2012). Sin embargo, los análisis estadísticos y comparativos que este organismo produce tienden a ignorar las características históricas y culturales de cada sistema educativo; a pesar de ello, la OCDE logra modificar y establecer políticas educativas en los ámbitos local, nacional y global (Sellar \& Lingard, 2013).

Los beneficios de concluir mayores niveles educativos van más allá de adquirir conocimientos y habilidades de utilidad para el mercado laboral, ya que los bienes individuales ganados a través de la EMS, como mayores niveles de salud, bienestar y participación ciudadana, así como la posibilidad de seguir aprendiendo a lo largo de la vida, pueden traducirse en niveles más altos de equidad social (Raudenbush \& Eschmann, 2015). No obstante la importancia que reviste la problemática actual de la EMS, la investigación educativa ha indagado poco sobre ella. Algunos análisis estadísticos han revelado persistentes niveles de deserción, bajas tasas de inscripción, retención y graduación en la región iberoamericana (Busso, Bassi \& Muñoz, 2013; Cárdenas, De Hoyos \& Székely, 2015; Kattan \& Székely, 2017). Estos estudios, aunque útiles, no pueden dar cuenta de las complejidades al interior de las escuelas y del proceso enseñanza-aprendizaje, las cuales son condicionadas por características históricas, sociales y culturales.

Hace ocho años, en 2010, la Organización de Estados Iberoamericanos (OEI) para la Educación, la Ciencia y la Cultura planteó las Metas Educativas 2021. Una de ellas es que los jóvenes de la región terminen doce años de educación que los puedan ayudar a tener un mejor futuro. De acuerdo con la OEI (2014), la tasa bruta de graduación de la EMS en la región en 2012-2013 fue de 57\%, aunque con diferencias significativas entre países. En los programas académicos de la EMS, la tasa bruta de graduación alcanzó 36\% en 2012-2013. En cuanto a los programas profesionales, la tasa bruta de graduación llegó a 25\% en el mismo periodo, pero, al igual que en los indicadores anteriores, existen diferencias significativas entre países.

Estas cifras indican que, sin considerar la tasa neta, es decir, la población en edad de recibir EMS (por lo regular entre los quince y diecisiete años de edad) a diferencia de la tasa bruta de graduación (la tasa total de graduación independientemente de la edad), la región iberoamericana, en general, tiene una baja participación en la EMS tanto en programas académicos que buscan preparar a los estudiantes para ciclos superiores como en programas profesionales que pueden insertarlos en el mundo laboral o prepararlos para seguir estudiando.

\footnotetext{
* Doctora en Sociología de la Educación por la Universidad de Bristol, Inglaterra. Académica de la Universidad de Southampton, Reino Unido. Su área de especialidad son las inequidades educativas y la exclusión social.
} 
Por citar un ejemplo, en México, los resultados nacionales de la EMS fueron publicados en forma reciente por el Instituto Nacional para la Evaluación de la Educación (INEE, 2017). En ellos se vislumbra que, tanto en lenguaje y comunicación como en matemáticas, la mayoría de los alumnos en este nivel presentan graves deficiencias en su aprendizaje. Los resultados muestran que, por cada 100 estudiantes que ingresan a la primaria, solo 56 logran terminar la EMS.

Los resultados también revelan que a menor capital económico de las familias y a menor nivel educativo de las madres, así como cuando ambos padres hablan alguna lengua indígena, más deficientes son los resultados de los alumnos. De igual modo, rezagos importantes fueron hallados en las escuelas de turno vespertino.

El número 51 de Sinéctica, Revista Electrónica de Educación busca dar cuenta de los retos, problemáticas y características actuales de este importante nivel educativo. Esperamos que este dossier aporte recomendaciones significativas a las prácticas y políticas educativas de la EMS.

\section{REFERENCIAS BIBLIOGRÁFICAS}

Busso, M., Bassi, M. \& Muñoz, J. (2013). Is the glass half empty or halffull? School enrollment, graduation, and dropout rates in Latin America. IDB Working Paper No. IDB-WP-462. http://dx.doi. org/10.2139/ssrn.2367706

Cárdenas, M., De Hoyos, R. \& Székely, M. (2015). Out-of-school and out-of-work youth in Latin America: A persistent problem in a decade of prosperity. Economía, vol. 16, núm. 1, pp. 1-40.

INEE (2017). Resultados nacionales de Planea. Educación media superior. INEE. Recuperado de http://www.inee.edu.mx/

Kattan, R. B. \& Székely, M. (2017). Analyzing Upper Secondary Education dropout in Latin America through a cohort approach. Journal of Education and Learning, vol. 6, núm. 4, pp. 12-39.

OCDE (2012). Equity and quality in education: Supporting disadvantaged students and schools. OECD Publishing. http://dx.doi.org/10.1787/9789264130852-en

OEI (2014). Miradas sobre la educación en Iberoamericana 2014. Avances en las Metas Educativas 2021. Recuperado de http://www.oei.es/historico/noticias/spip.php?article14386

Raudenbush, S. W. \& Eschmann, R. D. (2015). Does schooling increase or reduce social inequality? Annual Review of Sociology, vol. 41, núm. 1, pp. 443-470.

Sellar, S. \& Lingard, B. (2013). The OECD and global governance in education. Journal of Education Policy, vol. 28, núm. 5, pp. 710-725.

DOI:10.31391/S2007-7033(2018)0051-001 